\title{
Nanozyme-based lateral flow assay for the sensitive detection of Escherichia coli 0157:H7 in milk
}

\author{
Jiaojiao Han, ${ }^{\dagger} \dagger$ Lei Zhang, $†$ Liming Hu, ${ }^{*}$ Keyu Xing, ${ }^{*}$ Xuefei Lu, $†$ Youju Huang, $† \ddagger \S{ }^{1}$ Jiawei Zhang, $\dagger$ \\ Weihua Lai, ${ }^{* 1}$ and Tao Chen $^{1}$ \\ *State Key Laboratory of Food Science and Technology, Nanchang University, Nanchang 330047, China \\ †Key Laboratory of Marine Materials and Related Technologies, Zhejiang Key Laboratory of Marine Materials and Protective Technologies, \\ Ningbo Institute of Material Technology and Engineering, Chinese Academy of Sciences, Ningbo 315201, China \\ łUniversity of Chinese Academy of Sciences, 19A Yuquan Road, Beijing 100049, China \\ §Max Planck Institute for Polymer Research, Ackermannweg 10, 55128, Mainz, Germany
}

\begin{abstract}
Lateral flow assay (LFA) has been applied in many fields due to its relative ease of use and cost-effectiveness. However, it has low sensitivity and its applications are limited. Probe materials play a significant role in improving the detection efficiency and sensitivity of LFA. In this study, by using concave palladium-platinum (Pd-Pt) nanoparticles as a nanozyme probe, we developed a sensitive LFA based on the sandwich format for qualitative and quantitative detection of Escherichia coli O157:H7. The sensitivity of the LFA was improved by applying the $3,3^{\prime}, 5,5^{\prime}$-tetramethylbenzidine (TMB) substrate onto the test line where the nanozyme was accumulated in the presence of analytes. The nanozyme showed high catalytic performance toward TMB and greatly enhanced the signal intensity of the test line. The sensitivity of the nanozyme-based LFA was $9.0 \times$ $10^{2} \mathrm{cfu} / \mathrm{mL}$ in milk, which was 111-fold higher than that of traditional colloidal gold-based LFA. The proposed method has remarkable potential in the detection of various pathogens in real samples.
\end{abstract}

Key words: lateral flow assay, nanozyme, Escherichia coli $\mathrm{O} 157: \mathrm{H} 7,3,3^{\prime}, 5,5^{\prime}$-tetramethylbenzidine

\section{INTRODUCTION}

Food safety related to pathogens has attracted increasing attention as a public health problem (Duvenage and Korsten, 2017; Lemmons et al., 2011). Escherichia coli $\mathrm{O} 157: \mathrm{H} 7$, one of the important food-borne pathogens, is often associated with life-threatening diseases. Escherichia coli O157:H7 can cause hemorrhagic

\footnotetext{
Received January 11, 2018.

Accepted March 18, 2018.

${ }^{1}$ Corresponding authors: yjhuang@nimte.ac.cn, talktolaiwh@163. com, tao.chen@nimte.ac.cn
}

colitis, hemolysis, and acute kidney injury (Griffin and Tauxe, 1991; Paton and Paton, 1998). The US Centers for Disease Control (CDC) reported that outbreaks of E. coli $\mathrm{O} 157: \mathrm{H} 7$ are not limited to any specific type of food (CDC, 2017). Milk and its derived products, consumed daily in many countries, are easily contaminated by pathogens from their production to consumption (LeJune and Rajala-Schultz, 2009). Escherichia coli O157:H7 has been a common causative agent of disease in milk, and the infection dose is less than 100 cells (Tsiraki et al., 2018).

Traditional culture-based methods for the detection of pathogens are time-consuming and laborious (Ratnam et al., 1988; Ma et al., 2014). Other technologies, such as ELISA (Shan et al., 2016; Zeinhom et al., 2018), PCR (Bian et al., 2015; Dong et al., 2015), electrochemical strategy (Akanda et al., 2013; Barreirs dos Santos et al., 2013), localized surface plasmon resonance sensor (Wang et al., 2013; Song et al., 2017), and fluorescent biosensor (Chen et al., 2015; Leng et al., 2017), have been studied and exhibited short analysis time and high sensitivity. However, these methods require complex processing, trained personnel, and expensive analytical instruments, which are not suitable for resource-limited conditions. Consequently, simple, rapid, and sensitive methods are urgently needed to ensure food safety.

Lateral flow assay (LFA) is one promising candidate for the screening of relevant analytes because of its simplicity, low cost, and rapidness (Wang et al., 2015, 2017b,d; Choi et al., 2017). Gold nanoparticles (NP) are most commonly used as probes in LFA because of their unique optoelectronic properties, good biocompatibility, and long-term stability (Hou et al., 2007; Zhang et al., 2015; Cui et al., 2015; Wang et al., 2016a,c). However, traditional LFA based on Au NP is limited by its low sensitivity (Karakus and Salih, 2013; Luo et al., 2017).

In recent years, nanozymes have been widely used in biocatalysis, bioassays, and nanobiomedicine be- 
cause of their stability and low cost (Duan et al., 2015; Wang et al., 2016b; Gao et al., 2017). Here, we applied palladium-platinum (Pd-Pt) NP as a nanozyme probe in place of colloidal gold NP and generated a nanozyme-based LFA that was capable of detecting $E$. coli $\mathrm{O} 157 \mathrm{H}$ H at $9.0 \times 10^{2} \mathrm{cfu} / \mathrm{mL}$ in milk. In our study, sandwich-type immunoreactions were performed on the LFA and the Pd-Pt NP were accumulated on the test lines. The signal amplification is based on the Pd-Pt NP possessing excellent peroxidase-like activity toward 3,3',5,5'-tetramethylbenzidine (TMB; a chromogenic reagent), which can produce visual color band even at low concentrations of $E$. coli $\mathrm{O} 157: \mathrm{H} 7$. The nanozymebased LFA is a low-cost and user-friendly method for pathogen detection in real samples.

\section{MATERIALS AND METHODS}

\section{Materials and Equipment}

Pluronic F127, $\mathrm{K}_{2} \mathrm{PtCl}_{4}, \mathrm{Na}_{2} \mathrm{PdCl}_{4}$, ascorbic acid, and $\mathrm{K}_{2} \mathrm{CO}_{3}$ were purchased from Sigma-Aldrich (St. Louis, MO). Bovine serum albumin and PEG-20,000 were obtained from Beijing Biotech Co., Ltd. (Beijing, China). Nitrocellulose (NC) membrane was supplied by Millipore (Bedford, MA). Sample pad, conjugate pad, absorbent pad, and polyvinylchloride backing pad were purchased from Shanghai Kinbio Tech. Co., Ltd. (Shanghai, China). Anti-E. coli O157:H7 monoclonal antibody (mAb) and rabbit anti-E. coli O157:H7 polyclonal antibody (pAb) were received from Meridian Life Science Inc. (Memphis, TN). Milk was purchased from the supermarket. All other chemicals and reagent were of analytical reagent grade.

A XYZ-3050 Platform was supplied by BioDot (Irvine, CA). The test strip reader was obtained from Fenghang Scientific Instrument Co. Ltd. (Zhejiang, China). Transmission electron microscopy (TEM) and scanning transmission electron microscopy (STEM) images were acquired on a JEOL JEM 2010 electron microscope operating at $2.0 \mathrm{KV}$ (JEOL Ltd., Tokyo, Japan).

\section{Bacterial Strains}

Escherichia coli O157:H7 (ATCC 43888) and 11 nontarget strains were used in the study: E. coli (CMCC 44102), Listeria welshimeri (ATCC 35897), Enterobacter sakazakii (CMCC 45407), Proteus vulgaris (CMCC 49027), Shigella flexneri (CMCC 2457), Listeria monocytogenes (ATCC 13932), Pseudomonas aeruginosa (CMCC 11997), Micrococcus luteus (CMCC 28001), Salmonella Choleraesuis (ATCC 10708), Salmonella
Choleraesuis (CICC 21493), and Bacillus subtilis (BD 366). All strains were preserved in our laboratory.

\section{Preparation of Pd-Pt NP}

The Pd-Pt NP were synthesized as previously described with slight modifications (Ataee-Esfahani et al., 2013). The detailed experimental procedure is given in the Supplemental Material (https://doi.org/10.3168/ jds.2018-14429).

\section{Preparation of the Label-mAb Probe}

The label-mAb probe was prepared as previously reported with some modifications (Jiang et al., 2016). The $\mathrm{pH}$ of the Pd-Pt NP solution was adjusted with 0.2 mol/L $\mathrm{K}_{2} \mathrm{CO}_{3}$. Anti-E. coli O157:H7 mAb were added dropwise to $1 \mathrm{~mL}$ of the $\mathrm{Pd}-\mathrm{Pt} \mathrm{NP}$ solution, followed by gentle shaking at room temperature for $90 \mathrm{~min}$ for the formation of Pd-Pt NP-labeled mAb complex. The mixture was then blocked with $100 \mu \mathrm{L}$ of $1 \%$ (wt/vol) PEG-20,000 solution for $30 \mathrm{~min}$ and $100 \mu \mathrm{L}$ of $10 \%$ (wt/vol) BSA for $30 \mathrm{~min}$. Finally, the mixture was centrifuged at $1,780 \times g$ at $4^{\circ} \mathrm{C}$ for $10 \mathrm{~min}$. The precipitate was suspended in $100 \mu \mathrm{L}$ of eluent buffer containing $5 \%$ sucrose, $2 \%$ trehalose, 1\% PEG 20,000, 1\% BSA, and $0.25 \%$ Tween-20 (Beijing Biotech Co. Ltd., Beijing, China).

\section{Optimization of the LFA Parameters}

The $\mathrm{pH}$ of the $\mathrm{Pd}-\mathrm{Pt} \mathrm{NP}$ solution was adjusted to 7.0, 7.5, 8.0, 8.5, and 9.0, respectively. The label-mAb probe was prepared with of the anti- $E$. coli O157:H7 $\mathrm{mAb}$ solution at concentrations of 1.8, 2.8, 3.8, 4.8, and $5.8 \mu \mathrm{g} / \mathrm{mL}$, and the Pd-Pt NP solution was prepared at concentrations of $4,8,12,16,20$, and $24 \mu \mathrm{g} / \mathrm{mL}$. We used $2,3,4,5,6$, and $7 \mu \mathrm{L}$ of label-mAb probe for each test, respectively. Sterile PBS without E. coli O157:H7 (blank sample) and sterile PBS spiked with $10^{6} \mathrm{cfu} /$ $\mathrm{mL}$ of E. coli O157:H7 (positive sample) were used for this study.

\section{Preparation of LFA}

The structure of LFA is shown in Figure 1. The sample pad, conjugate pad, NC membrane, and absorption pad were assembled on a backing pad to form the test strip. The sample pad was pretreated with $20 \mathrm{mM}$ sodium buffer containing 1.0\% (wt/vol) BSA, $0.05 \%$ (wt/vol) $\mathrm{NaN}_{3}$, and $0.5 \%$ (vol/vol) Tween 20 and then dried at $60^{\circ} \mathrm{C}$ for $2 \mathrm{~h}$. The anti-E. coli $\mathrm{O} 157: \mathrm{H} 7 \mathrm{pAb}$ and goat anti-mouse IgG were sprayed on the NC mem- 
brane as the test and control line, respectively, and the $\mathrm{NC}$ membrane was dried at $37^{\circ} \mathrm{C}$ for $16 \mathrm{~h}$.

\section{Detection of LFA}

The label-mAb probes were premixed with $100 \mu \mathrm{L}$ of the sample in the microwell at room temperature for $5 \mathrm{~min}$, and then the mixture was pipetted to the sample pad of the test strip. After a certain time, the TMB solution that contained $\mathrm{H}_{2} \mathrm{O}_{2}$ was added, the final signal intensity of the test line was recorded by the portable strip reader.

\section{Immunological Kinetics Analysis of LFA}

The immunological kinetic curves of the test and control lines were obtained through the following procedures, First, $100 \mu \mathrm{L}$ of the sample incubated with
label-mAb probes was dropped into the sample pad of the test strip. After $2 \mathrm{~min}$, the strip was inserted into the portable test strip reader. The signal intensities of test and control lines $\left(\mathbf{I}_{\mathbf{T}}\right.$ and $\mathbf{I}_{\mathbf{C}}$, respectively) were recorded every $30 \mathrm{~s}$. The immunological kinetic curves were established by plotting the $\mathrm{I}_{\mathrm{T}}$ and the $\mathrm{I}_{\mathrm{C}}$ against time.

\section{Dynamic Analysis of TMB Catalytic Reaction on Test Line}

When the immunoreaction on the test line was complete, TMB solution containing $\mathrm{H}_{2} \mathrm{O}_{2}$ was added to the test line of the strips. After 2 or $3 \mathrm{~min}$, the $\mathrm{I}_{\mathrm{T}}$ was recorded every $60 \mathrm{~s}$. The dynamic curves of the TMB catalytic reaction were established by plotting $\mathrm{I}_{\mathrm{T}}$ against time.

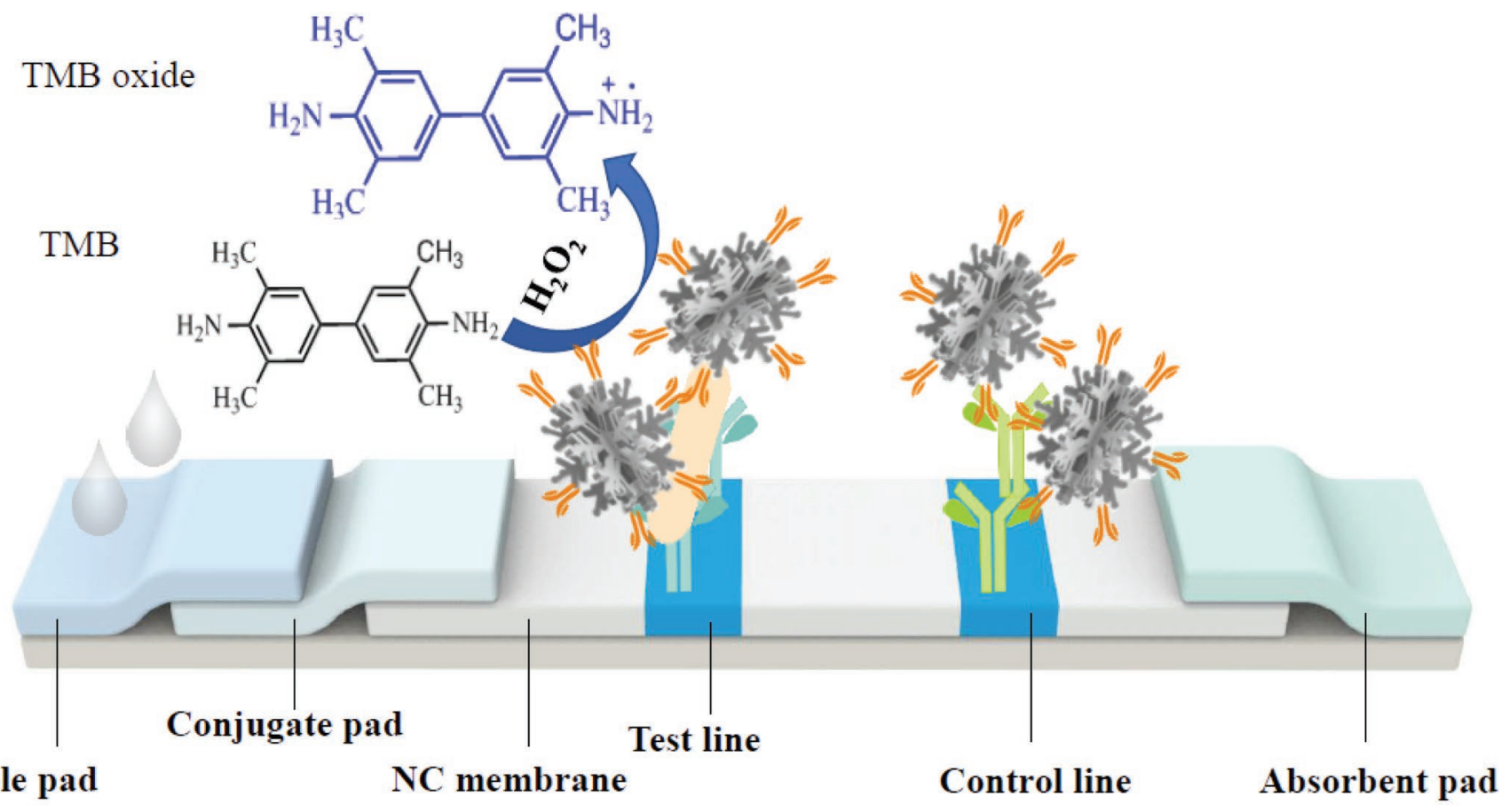

E. coli 0157:H7

Pd-Pt NPs-labelled antibody

Anti-E. coli $\mathrm{O} 157: \mathrm{H} 7$ polyclonal antibody

\section{Goat anti-mouse IgG}

Figure 1. Schematic illustration of the proposed lateral flow assay for the detection of Escherichia coli O157:H7. TMB = 3,3',5,5'-tetramethylbenzidine; $\mathrm{NC}=$ nitrocellulose; $\mathrm{NP}=$ nanoparticles. Color version available online. 

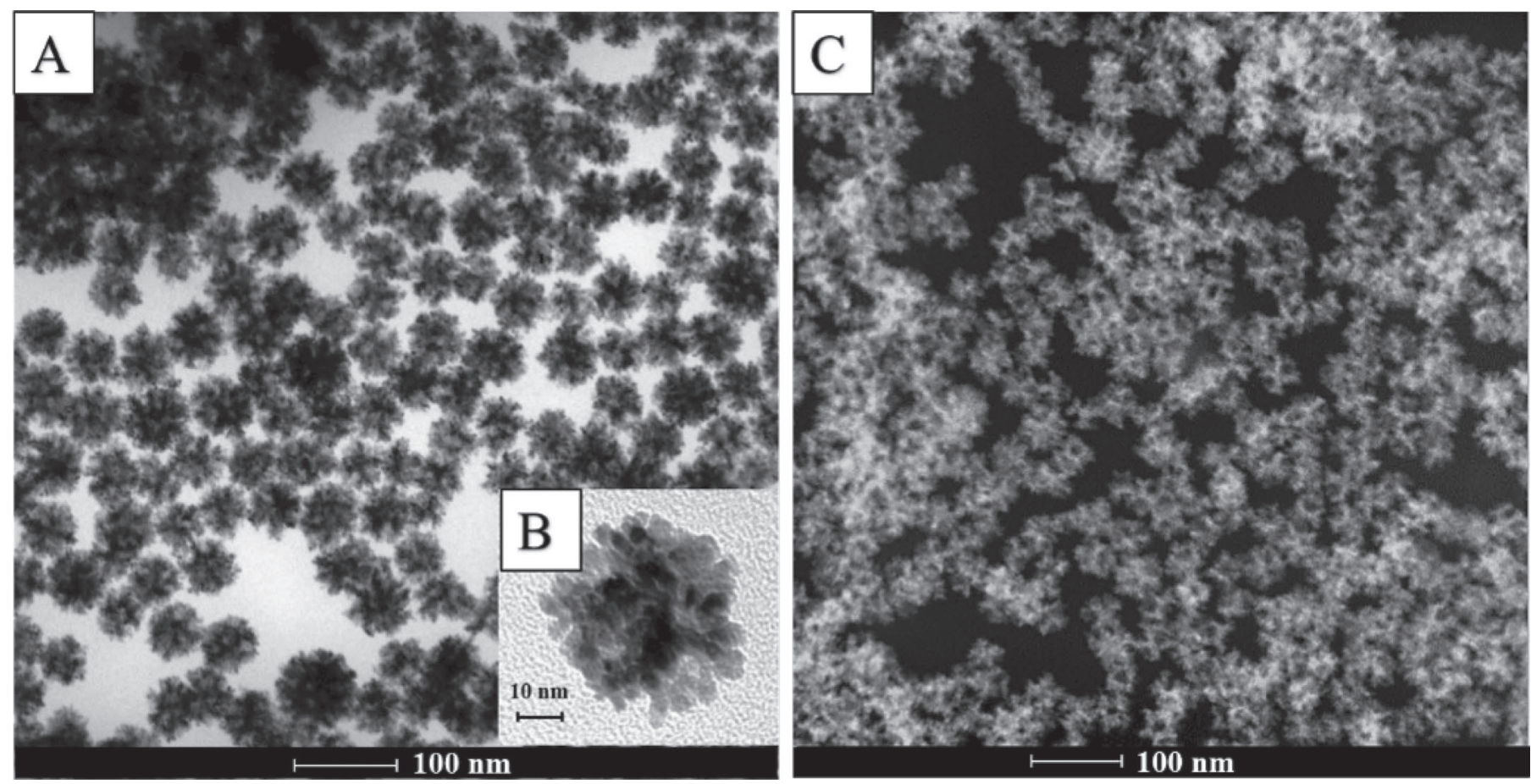

Figure 2. (A) Transmission electron microscopy (TEM) image, (B) magnified TEM image, and (C) scanning TEM image of Pd-Pt nanoparticles.

\section{Standard Calibration Curve of LFA}

The standard calibration curve was established by plotting the $\mathrm{I}_{\mathrm{T}}$ against the logarithm of the concentration of $E$. coli $\mathrm{O} 157: \mathrm{H} 7\left(0,1.0 \times 10^{2}, 5.0 \times 10^{2}, 1.0 \times\right.$ $10^{3}, 5.0 \times 10^{3}, 1.0 \times 10^{4}, 5.0 \times 10^{4}, 1.0 \times 10^{5}, 5.0 \times$ $10^{5}, 1.0 \times 10^{6}$, and $1.0 \times 10^{7} \mathrm{cfu} / \mathrm{mL}$ ) by diluting $E$. coli O157:H7 solution $\left(10^{8} \mathrm{cfu} / \mathrm{mL}\right)$ with $0.01 \mathrm{MPBS}$ ( $\mathrm{pH}$ 7.4) or milk. The matrix effect was identified by comparing the standard calibration curves and the sensitivity in spiked PBS with those in milk.

\section{Specificity of LFA}

The specificity of the LFA was estimated by testing 12 bacterial strains, including the E. coli $\mathrm{O} 157: \mathrm{H} 7$ target strain $\left(1.0 \times 10^{6} \mathrm{cfu} / \mathrm{mL}\right)$, and 11 nontarget strains $\left(1.0 \times 10^{6} \mathrm{cfu} / \mathrm{mL}\right)$. A control test was performed with sterile milk. The experiment was performed in triplicate.

\section{RESULTS AND DISCUSSION}

\section{Characteristics of Pd-Pt NP}

Bimetallic nanoparticles are attracting considerable attention because it is superior to monometallic nanoparticles with respect to catalytic activity (Gu et al., 2012; Wang et al., 2017a). In our study, concave Pd-Pt NP were synthetized as probes for rapid on-site detection. The Pd-Pt NP had more surface area than its monometallic nanoparticles and gold nanoparticles, thereby providing many catalytically active sites. Both TEM and STEM were performed for the characterization of the obtained Pd-Pt NP (Figure 2). Hemispherical porous structures with concavities were confirmed by STEM, and several branched structures were observed on the surfaces of the NP. The Pd-Pt NP were relatively uniform in size $(\sim 40 \mathrm{~nm})$.

\section{Peroxidase-Like Catalytic Activities of Pd-Pt NP}

Using peroxidase substrate TMB, we studied the peroxidase-like catalytic activities of $\mathrm{Pd}-\mathrm{Pt} \mathrm{NP}$ through colorimetric tests. The results indicated that the $\mathrm{Pd}-\mathrm{Pt}$ NP catalyzed $\mathrm{H}_{2} \mathrm{O}_{2}$-induced TMB oxidation, resulting in a deep blue color solution within 10 min (Supplemental Figure S1A; https://doi.org/10.3168/jds.2018 -14429). This result indicated that the Pd-Pt NP acted as peroxidases for TMB oxidation in the presence of $\mathrm{H}_{2} \mathrm{O}_{2}$. The TMB oxide had 2 strong UV-visible absorption peaks at 370 and $652 \mathrm{~nm}$ (Supplemental Figure S1B). All of the following experiments on absorbance were measured at $652 \mathrm{~nm}$. 
We examined the thermal and $\mathrm{pH}$ stability of the porous Pd-Pt NP. As shown in Supplemental Figure S2A (https://doi.org/10.3168/jds.2018-14429), the PdPt NP exhibited stable enzymatic catalytic activity toward TMB at 0 to $60^{\circ} \mathrm{C}$, and the absorbance of TMB oxide was approximately 2.20 . As the temperature continued to rise, the absorbance decreased, with values of 1.86 and 1.80 at 75 and $90^{\circ} \mathrm{C}$, respectively. As shown in Supplemental Figure S2B, the activities of the Pd$\mathrm{Pt} \mathrm{NP}$ were also tested in solutions with $\mathrm{pH}$ values ranging from 2.0 to 12.0. The highest absorbance was 3.00 at $\mathrm{pH} 8.0$ and the lowest was 2.42 at $\mathrm{pH} 2.0$. As shown in Supplemental Figure S2C, the absorbance of TMB oxide depended on the concentration of Pd-Pt NP. Ranging from 0.4 to $8 \mu \mathrm{g} / \mathrm{mL}$, the absorbance increased with the increase in NP concentration. Furthermore, the TMB- $\mathrm{H}_{2} \mathrm{O}_{2}$ assay of Pd-Pt NP achieved higher absorbance than commercial $\mathrm{Pd}$ nanopowders at the same concentrations of catalysts, indicating that Pd-Pt NP oxidize more TMB with the same amount of NP.

The steady-state kinetic parameters of Pd-Pt NP were further carried out by changing one concentration of TMB or $\mathrm{H}_{2} \mathrm{O}_{2}$ and keeping the other at the same time. Michaelis-Menten curves were obtained, as shown in Supplemental Figure S3 (https://doi.org/10.3168/ jds.2018-14429). The data were fitted to LineweaverBurk equation to acquire the Michaelis-Menten constant $\left(\boldsymbol{K}_{m}\right)$. The apparent $K_{m}$ value toward TMB is $3.11 \mathrm{~m} M$, whereas the $K_{m}$ toward $\mathrm{H}_{2} \mathrm{O}_{2}$ is $33.40 \mathrm{~m} M$.

\section{Optimization of LFA}

The LFA was developed on the basis of the sandwich immunoassay principle (Figure 1). With positive samples, the label-mAb probe (Pd-Pt NP-labeled antibody) would capture the analyte and migrate along the NC membrane by capillary. The sandwich immunoreaction was achieved on the test line. When the sample was free of analytes, the label-mAb probe was not captured by the anti- $E$. coli O157:H7 pAb immobilized on the test line. This resulted in the signal intensity on the test line changing from weak to strong with increasing concentrations of the analyte. Whatever, the label-mAb probe was bound by the goat anti-mouse IgG immobilized on the control line. Signal amplification was based on the Pd-Pt NP, which catalyzed colorless TMB, producing a visible blue product in the presence of $\mathrm{H}_{2} \mathrm{O}_{2}$.

The labeling $\mathrm{pH}$, which affects antibody activity and coupling efficiency (Chen et al., 2013), was optimized and analyzed by studying the signal intensity of the $\mathrm{I}_{\mathrm{T}}$. When the labeling $\mathrm{pH}$ was adjusted to 7.0, 7.5, 8.0, 8.5, or 9.0, the $\mathrm{I}_{\mathrm{T}}$ values of test-positive samples were 1,001 ,
$1,339,1,144,40$, and 48, respectively (Figure 3A). The optimal labeling $\mathrm{pH}$ was 7.5 because the $\mathrm{I}_{\mathrm{T}}$ of the positive sample was high, whereas that of the blank sample was low.

The effect of anti- $E$. coli $\mathrm{O} 157: \mathrm{H} 7 \mathrm{mAb}$ concentration was investigated. As shown in Figure $3 \mathrm{~B}$, the $\mathrm{I}_{T}$ gradually increased at increased anti- $E$. coli $\mathrm{O} 157: \mathrm{H} 7$ $\mathrm{mAb}$ concentration. The strongest intensity $(1,977)$ was obtained at a concentration $3.8 \mu \mathrm{g} / \mathrm{mL}$ of anti- $E$. coli O157:H7 mAb. Therefore, this concentration was selected for the coupling with the Pd-Pt NP.

The concentration of the Pd-Pt NP was also a key factor for their coupling with the antibodies. As shown in Figure 3C, the $\mathrm{I}_{\mathrm{T}}$ gradually increased when the concentration of the Pd-Pt NP solution increased. The strongest intensity was 1,803 and the $\mathrm{I}_{\mathrm{T}}$ of the blank sample was weak; therefore, the optimal concentration of Pd-Pt NP was $20 \mu \mathrm{g} / \mathrm{mL}$.

The volume of label-mAb probe used for each test was discussed. As shown in Figure 3D, the $\mathrm{I}_{\mathrm{T}}$ increased as the probe volume increased up to $6 \mu \mathrm{L}$; nNo increase was observed at $7 \mu \mathrm{L}$. Because of the strong $\mathrm{I}_{\mathrm{T}}$ of the positive sample and weak $\mathrm{I}_{\mathrm{T}}$ of the blank sample, $6 \mu \mathrm{L}$ of the label-mAb probe was selected for all subsequent experiments.

\section{Immunological Kinetics Analysis of LFA}

Immunological kinetic curves were established by plotting $\mathrm{I}_{\mathrm{T}}$ against time. As shown in Supplemental Figure S4 (https://doi.org/10.3168/jds.2018-14429), the $\mathrm{I}_{\mathrm{T}}$ tended to be steady at $25 \mathrm{~min}$ when the positive sample (spiked PBS) was added to the sample pad of the test strip, whereas the $\mathrm{I}_{\mathrm{T}}$ of the blank sample was weak even after $35 \mathrm{~min}$. As shown in Supplemental Figure S5 (https://doi.org/10.3168/jds.2018-14429), the $\mathrm{I}_{\mathrm{T}}$ also tended to be steady at $25 \mathrm{~min}$ when the substrate was milk, whereas that of the blank sample remained weak. These data indicated that the immunoreaction time of the spiked PBS sample was not much different from that of the milk sample, and 25 min was sufficient for LFA detection before the TMB solution was added to the test strip.

\section{Dynamic Analysis of TMB Catalytic Reaction on the Test Line}

As shown in Supplemental Figure S6 (https://doi .org/10.3168/jds.2018-14429), the reaction time showed an obvious effect on catalytic response after the addition of TMB. The highest responses were obtained after the TMB was added to the test line with spiked PBS sample for 4 min (Supplemental Figure S6A) and 
MVI $\mathrm{I}_{\mathrm{T}}$ (Positive)

$\square \mathbf{I}_{\mathrm{I}}$ (Blank)

A

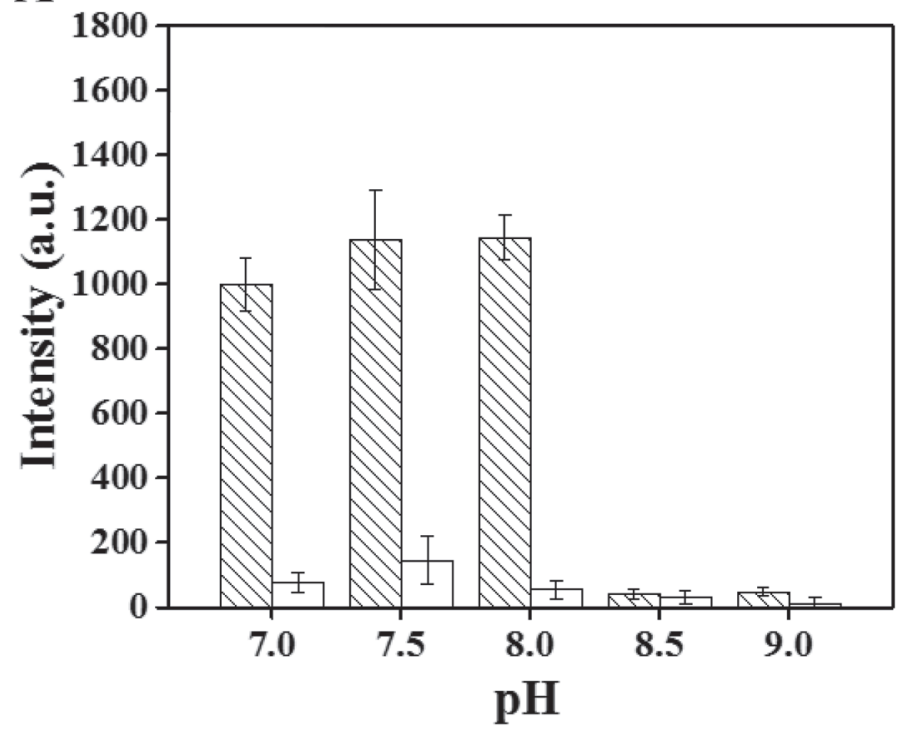

C

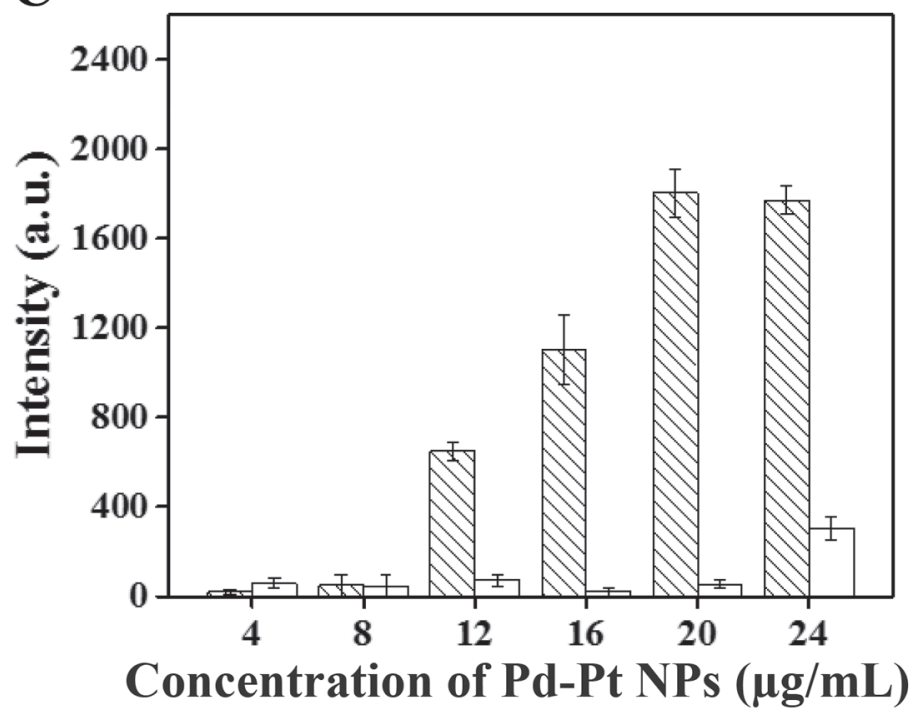

B

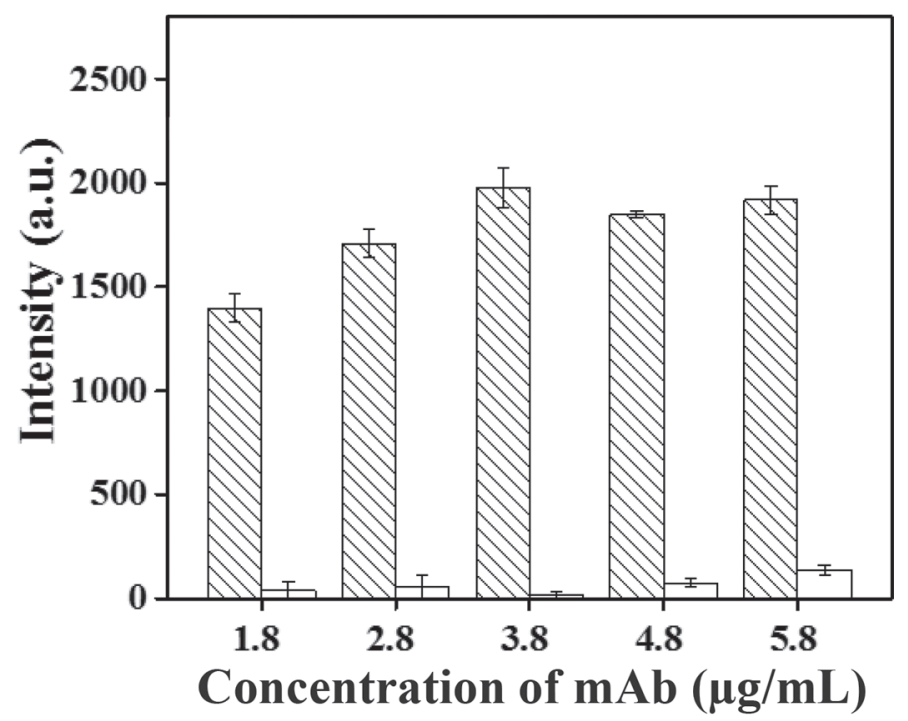

D

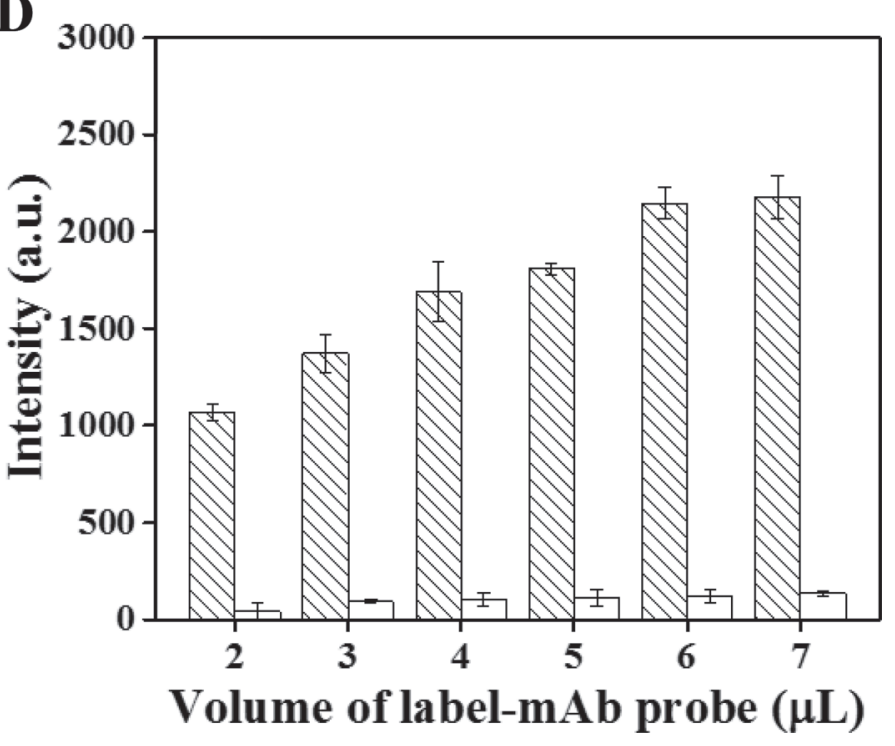

Figure 3. (A) Optimization of labeling $\mathrm{pH}$, (B) optimization of concentration of monoclonal antibody (mAb) conjugated with $\mathrm{Pd}-\mathrm{Pt}$ nanoparticles (NP), (C) optimization of concentration of Pd-Pt NP conjugated with mAb, and (D) optimization of the volume of label-mAb probe used for each test. $\mathrm{I}_{\mathrm{T}}=$ signal intensities of the test line. Error bars indicate the $\mathrm{SD}(\mathrm{n}=3)$.

that with spiked milk sample for 8 min (Supplemental Figure S6B). The intensity increased because of the intensified TMB oxidation. Over time, the intensity decreased, and a blurred line occurred because of the diffusion. The experimental results showed that milk substrate affected the catalytic response, and the signal intensity of the test line can be enhanced by appropriately extending the reaction time.

\section{Standard Calibration Curves of LFA}

The standard calibration curve was established under optimal experimental conditions. The signal intensity of the test line was recorded, and the obtained data were applied for the quantitative analysis of $E$. coli $\mathrm{O} 157: \mathrm{H} 7$. Sensitivity was defined as the mean plus 3 -fold standard deviation of the negative sample (Oh et al., 2009). 
Escherichia coli O157:H7 can be qualitatively detected by observing the blue band on the test line of the test strip.

The results of the experiment performed with spiked PBS are shown in Figure 4. The regression equation was $\mathrm{y}=777.42 \lg (\mathrm{C})-928.13$ and ranged from $1 \times$ $10^{2}$ to $1 \times 10^{6} \mathrm{cfu} / \mathrm{mL}$ with the reliable correlation coefficients of 0.9869 . The calculated sensitivity was $0.87 \times 10^{2} \mathrm{cfu} / \mathrm{mL}$, and the sensitivity observed by the naked eye was $1 \times 10^{2} \mathrm{cfu} / \mathrm{mL}$ in PBS. The correlative standard calibration curve and photograph of the strips without TMB were shown in Supplemental Figure S7 (https://doi.org/10.3168/jds.2018-14429), and the related sensitivity observed by the naked eye was $1 \times 10^{4}$ $\mathrm{cfu} / \mathrm{mL}$ in PBS.
The experiment was also performed with spiked milk. The data indicated that the $\mathrm{I}_{\mathrm{T}}$ increased with increased E. coli O157:H7 concentrations. As shown in Figure 5, the regression equation was y $=963.42 \lg (\mathrm{C})$ $-2,506.05$ and ranged from $1 \times 10^{3}$ to $1 \times 10^{6} \mathrm{cfu} /$ $\mathrm{mL}$ with the reliable correlation coefficients of 0.9857 . The calculated sensitivity was $9.0 \times 10^{2} \mathrm{cfu} / \mathrm{mL}$, and the sensitivity observed by the naked eye was $1 \times 10^{3}$ $\mathrm{cfu} / \mathrm{mL}$ in milk. The correlative standard calibration curve and the photograph of the strips without TMB are shown in Supplemental Figure S8 (https://doi.org/ 10.3168/jds.2018-14429), and the related sensitivity observed by the naked eye was $5.0 \times 10^{4} \mathrm{cfu} / \mathrm{mL}$ in milk.

A comparison of materials, sensitivity, and linear ranges between this method and other methods for
A

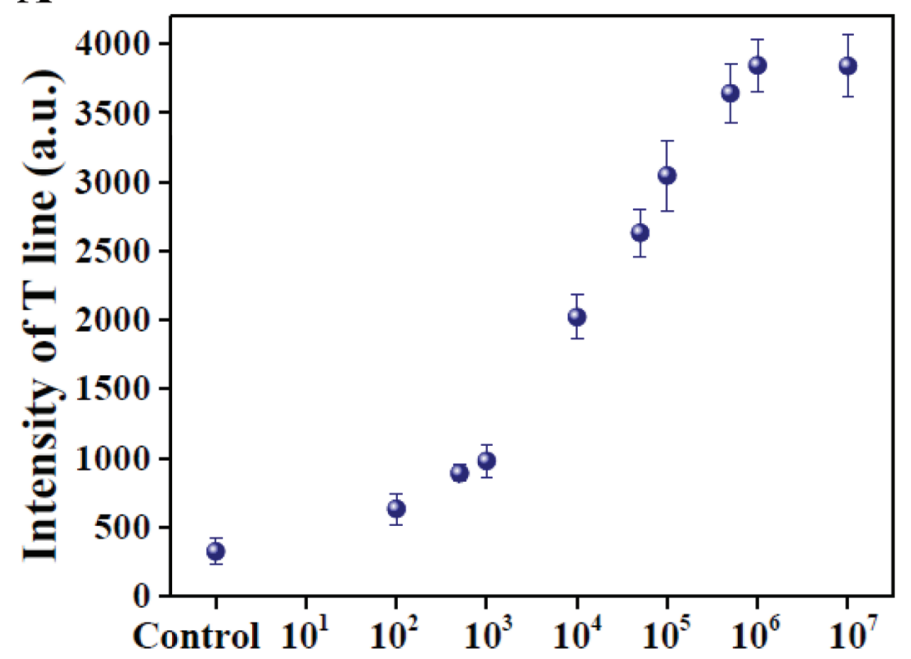

B

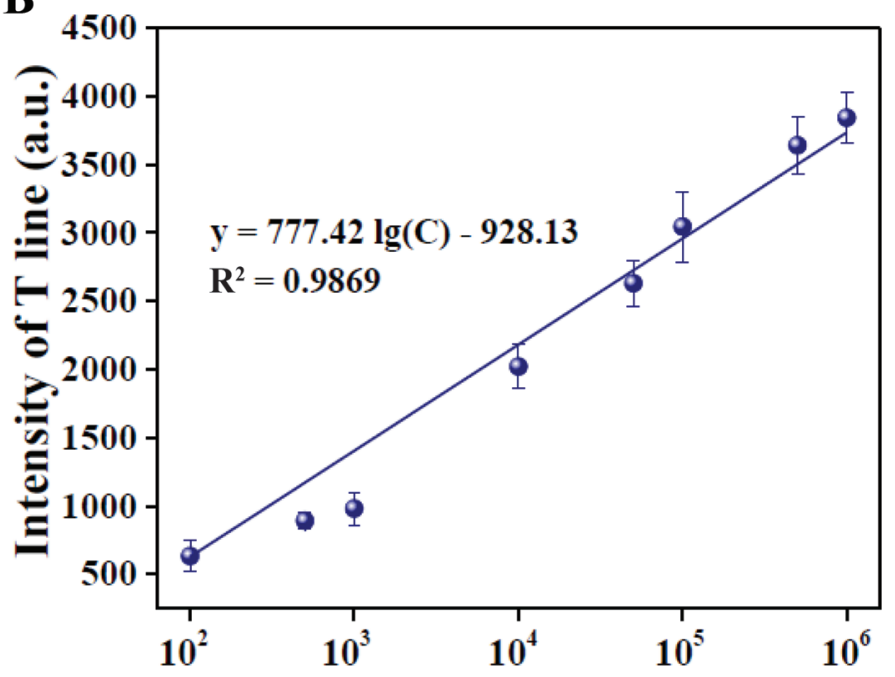

C

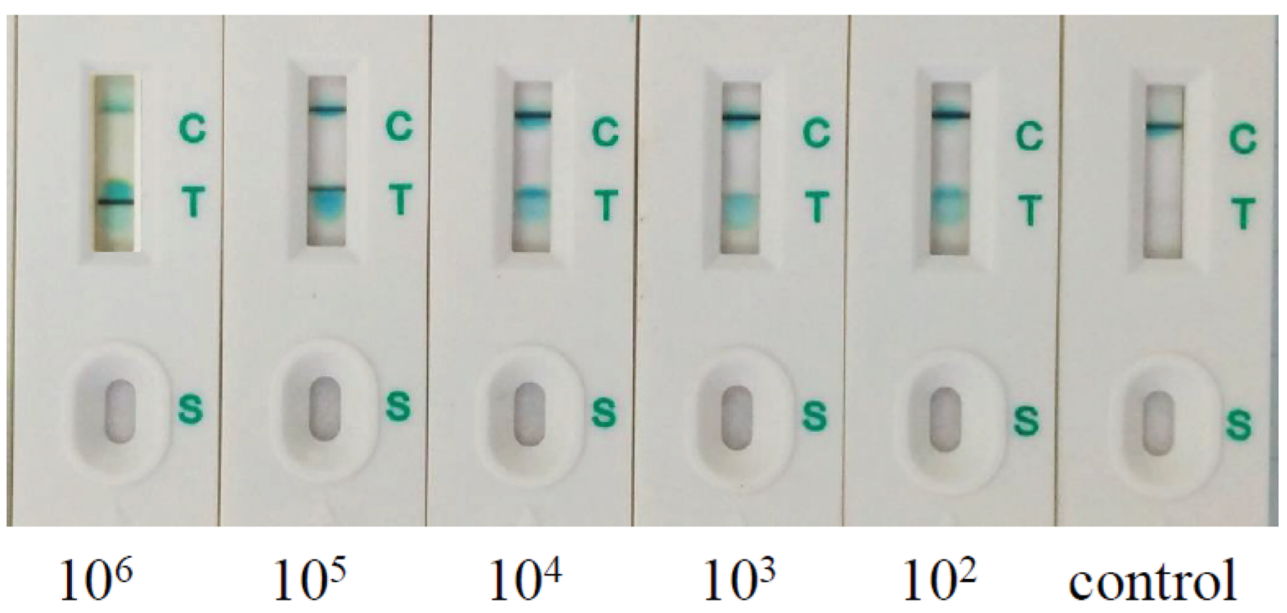

\section{Concentration of $E$. coli 0157:H7 (cfu/mL)}

Figure 4. Relationship between Escherichia coli O157:H7 concentration and the signal intensity of the test line with PBS buffer. (A) Standard curve and (B) related linear curve of the lateral flow strip for the detection of E. coli O157:H7; (C) photograph of the strips with 3,3',5,5'-tetramethylbenzidine. $\mathrm{C}=$ control line; $\mathrm{T}=$ test line; $\mathrm{S}=$ sample zone. Error bars indicate the $\mathrm{SD}(\mathrm{n}=3)$. Color version available online. 
A

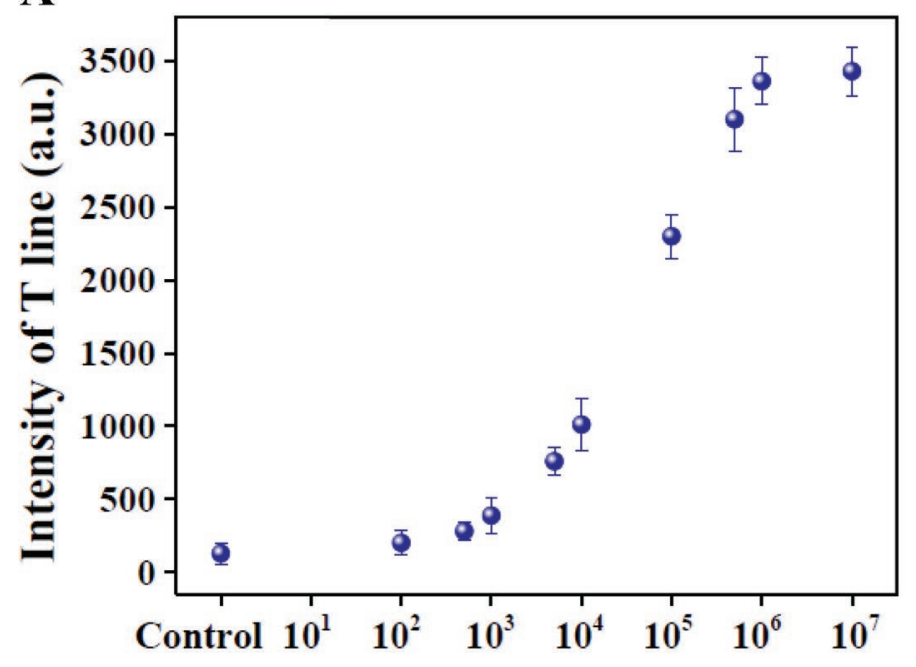

B

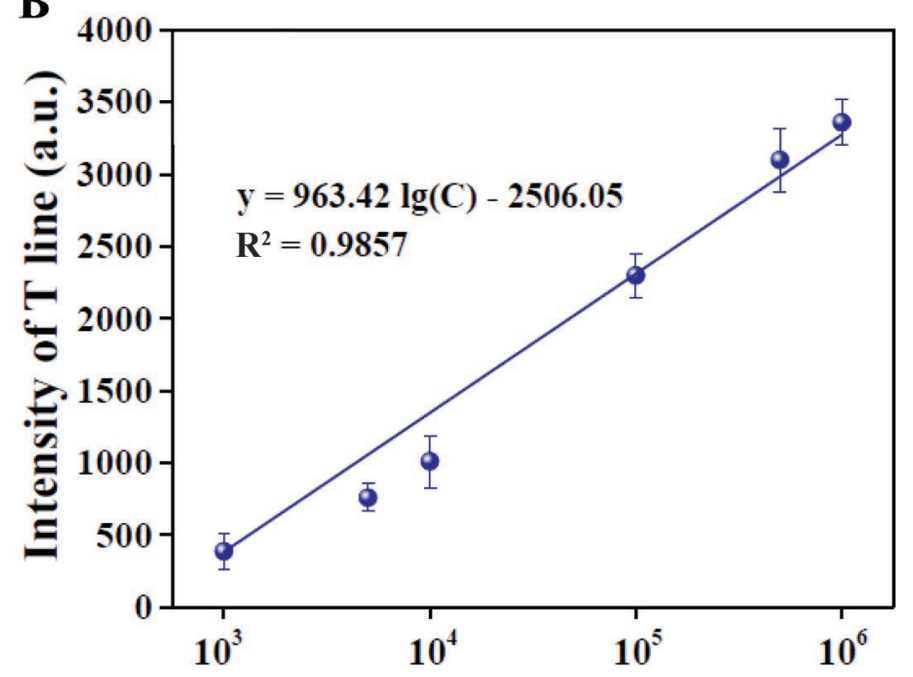

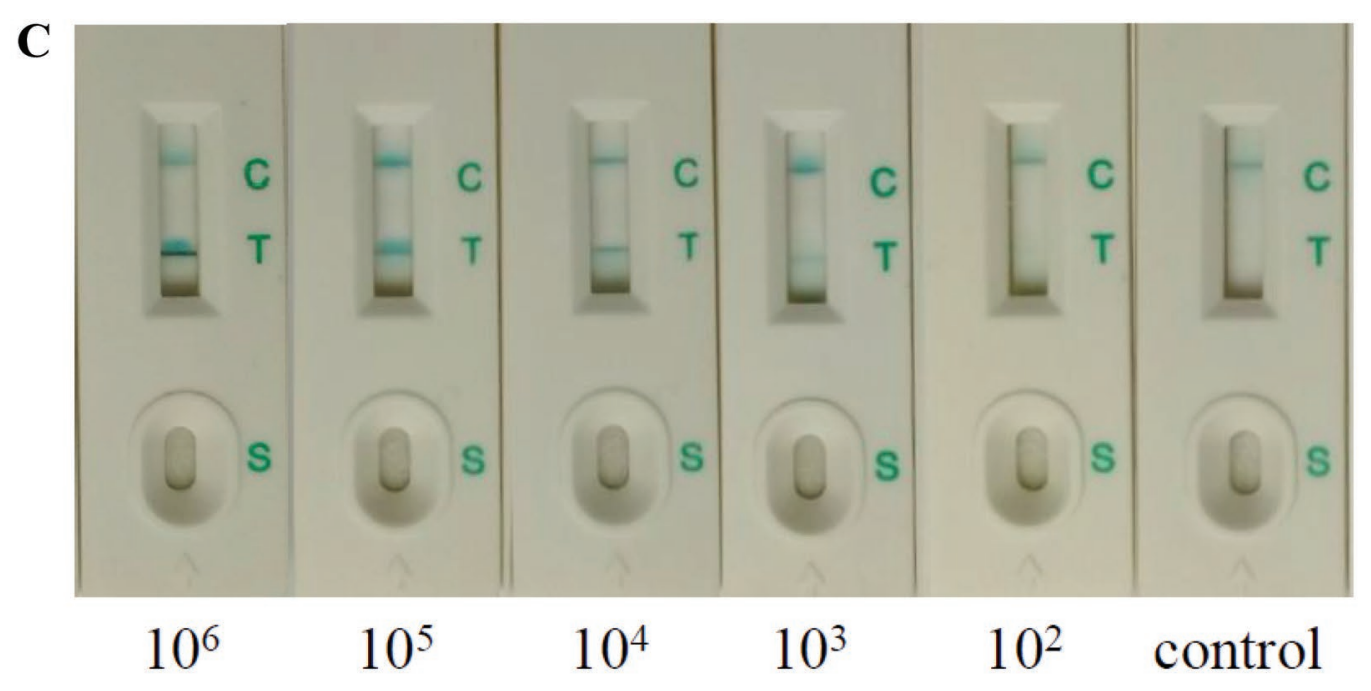

\section{Concentration of $\mathrm{E}$. coli $\mathrm{O} 157: \mathrm{H} 7$ (cfu/mL)}

Figure 5. Relationship between Escherichia coli O157:H7 concentration and the signal intensity of the test line with milk substrate. (A) Standard curve and (B) the related linear curve of the lateral flow strip for the detection of E. coli O157:H7; (C) photograph of the strips with $3,3^{\prime}, 5,5^{\prime}$-tetramethylbenzidine. $\mathrm{C}=$ control line; $\mathrm{T}=$ test line; $\mathrm{S}=$ sample zone. Error bars indicate the $\mathrm{SD}(\mathrm{n}=3)$. Color version available online.

detection of E. coli $\mathrm{O} 157: \mathrm{H} 7$ reported previously was listed in Supplemental Table S1 (https://doi.org/10 .3168/jds.2018-14429). Compared with other methods, the method we established offered a comparable or superior linear range and sensitivity.

\section{Specificity of LFA}

The specificity, which is the most encountered problem for the LFA (Sajid et al., 2015), was evaluated by testing E. coli O157:H7 $\left(1 \times 10^{6} \mathrm{cfu} / \mathrm{mL}\right)$ and other 11 non- $E$. coli $\mathrm{O} 157: \mathrm{H} 7$ strains $\left(1 \times 10^{6} \mathrm{cfu} / \mathrm{mL}\right)$. As shown in Figure 6, the $\mathrm{I}_{\mathrm{T}}$ of E. coli O157:H7 sample was strong $(3,300)$, and the $\mathrm{I}_{\mathrm{T}}$ values of the other samples ranged from 138 to 320 . This result indicated that this LFA had high specificity toward E. coli O157:H7.

\section{CONCLUSIONS}

In summary, a sensitive LFA for the analysis of E. coli O157:H7 was developed on the basis of the nanozyme. The concave Pd-Pt NP we prepared not only acted as nanozyme probes but also exhibited a great magnified effect. The detectable response of the LFA was greatly enhanced because of the excellent peroxidase-like activity of the Pd-Pt NP toward TMB. Thus, the LFA 


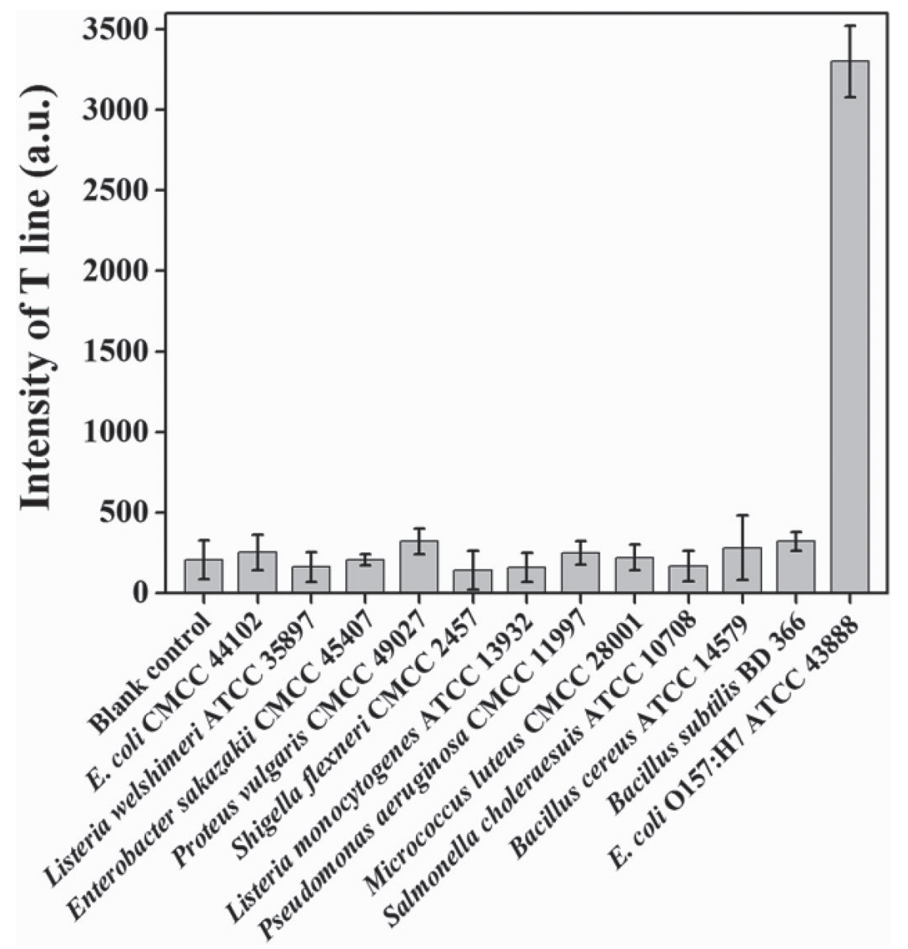

Figure 6. Specificity of the proposed lateral flow assay over other non-Escherichia coli O157:H7. Error bars indicate the SD (n = 3).

showed obvious visual color on the test line of strips, even at the low concentration range of the target. The sensitivity of the proposed LFA was $0.87 \times 10^{2} \mathrm{cfu} /$ $\mathrm{mL}$ in PBS, and $9.0 \times 10^{2} \mathrm{cfu} / \mathrm{mL}$ in milk. As a result, the nanozyme-based LFA is a low-cost and easy-to-use method for the rapid screening of pathogens in milk.

\section{ACKNOWLEDGMENTS}

We gratefully acknowledge the Natural Science Foundation of China (Grant Nos. 51473179, 21404110, 31772066), the Bureau of Frontier Science and Education of Chinese Academy of Sciences (QYZDB-SSWSLH036), Fujian province-Chinese Academy of Sciences STS project (2017T31010024), Ningbo Science and Technology Bureau (2015C110031), Youth Innovation Promotion Association of Chinese Academy of Science (2016268 and 2017337) and the Open Project Program of State Key Laboratory of Food Science and Technology, Nanchang University (China, No. SKLFKF-201616).

\section{REFERENCES}

Akanda, M. R., V. Tamilavan, S. Park, K. Jo, M. H. Hyun, and H. Yang. 2013. Hydroquinone diphosphate as a phosphatase substrate in enzymatic amplification combined with electrochemical-chemi- cal-chemical redox cycling for the detection of E. coli O157: H7. Anal. Chem. 85:1631-1636.

Ataee-Esfahani, H., M. Imura, and Y. Yamauchi. 2013. All-metal mesoporous nanocolloids: Solution-phase synthesis of core-shell Pd@ Pt nanoparticles with a designed concave surface. Angew. Chem. Int. Ed. Engl. 52:13611-13615.

Barreiros dos Santos, M., J. P. Agusil, B. Prieto-Simón, C. Sporer, V. Teixeira, and J. Samitier. 2013. Highly sensitive detection of pathogen Escherichia coli O157:H7 by electrochemical impedance spectroscopy. Biosens. Bioelectron. 45:174-180.

Bian, X., F. Jing, G. Li, X. Fan, C. Jia, H. Zhou, Q. Jin, and J. Zhao. 2015. A microfluidic droplet digital PCR for simultaneous detection of pathogenic Escherichia coli O157 and Listeria monocytogenes. Biosens. Bioelectron. 74:770-777.

Centers for Disease Control and Prevention (CDC). 2017. Reports and Selected E. coli Outbreak Investigations. Accessed Feb. 27, 2017. https://www.cdc.gov/ecoli/outbreaks.html.

Chen, Y., Y. Xin, H. Yang, L. Zhang, Y. Zhang, X. Xiao, Y. Tong, and W. Wang. 2013. Immobilization and stabilization of cholesterol oxidase on modified sepharose particles. Int. J. Biol. Macromol. $56: 6-13$.

Chen, Z. Z., L. Cai, M. Y. Chen, Y. Lin, D. W. Pang, and H. W. Tang, 2015. Indirect immunofluorescence detection of E. coli O157: H7 with fluorescent silica nanoparticles. Biosens. Bioelectron. 66:95102.

Choi, J. R., K. W. Yong, R. Tang, Y. Gong, T. Wen, H. Yang, A. Li, Y. C. Chia, B. Pingguan-Murphy, and F. Xu. 2017. Lateral flow assay based on paper-hydrogel hybrid material for sensitive pointof-care detection of dengue virus. Adv. Healthc. Mater. 6:1600920.

Cui, X., Y. Huang, J. Wang, L. Zhang, Y. Rong, W. Lai, and T. Chen. 2015. A remarkable sensitivity enhancement in a gold nanoparticle-based lateral flow immunoassay for the detection of Escherichia coli O157:H7. RSC Advances 5:45092-45097.

Dong, L. H., L. Zhang, J. Jing, J. N. Wang, J. Wang, and W. J. Chen. 2015. Development of droplet digital polymerase chain reaction for quantifying Escherichia coli O157:H7. Chin. J. Anal. Chem. 43:319-324.

Duan, D., K. Fan, D. Zhang, S. Tan, M. Liang, Y. Liu, J. Zhang, P. Zhang, W. Liu, X. Qiu, G. P. Kobinger, G. F. Gao, and X. Yan. 2015. Nanozyme-strip for rapid local diagnosis of Ebola. Biosens. Bioelectron. 74:134-141.

Duvenage, S., and L. Korsten. 2017. Assessment of foodborne pathogen presence in the peach supply chain and its potential risk to the end consumer. Food Control 78:374-382.

Gao, L., K. Fan, and X. Yan. 2017. Iron oxide nanozyme: A multifunctional enzyme mimetic for biomedical applications. Theranostics $7: 3207-3227$.

Griffin, P. M., and R. V. Tauxe. 1991. The epidemiology of infections caused by Escherichia coli O157: H7, other enterohemorrhagic $E$ coli, and the associated hemolytic uremic syndrome. Epidemiol. Rev. 13:60-98.

Gu, J., Y. W. Zhang, and F. F. Tao. 2012. Shape control of bimetallic nanocatalysts through well-designed colloidal chemistry approaches. Chem. Soc. Rev. 41:8050-8065.

Hou, S. Y., H. K. Chen, H. C. Cheng, and C. Y. Huang. 2007. Development of zeptomole and attomolar detection sensitivity of biotinpeptide using a dot-blot gold nanoparticle immunoassay. Anal. Chem. 79:980-985.

Jiang, T., Y. Song, T. Wei, H. Li, D. Du, M. J. Zhu, and Y. Lin. 2016. Sensitive detection of Escherichia coli O157: H7 using Pt-Au bimetal nanoparticles with peroxidase-like amplification. Biosens. Bioelectron. 77:687-694.

Karakus, C., and B. A. J. Salih. 2013. Comparison of lateral flow immunoassays (LFIA) for the diagnosis of Helicobacter pylori infection. J. Immunol. Methods 396:8-14.

LeJeune, J. T., and P. J. Rajala-Schultz. 2009. Unpasteurized milk: A continued public health threat. Clin. Infect. Dis. 48:93-100.

Lemmons, J. L., L. M. Lucia, M. D. Hardin, J. W. Savell, and K. B. Harris. 2011. Evaluation of Escherichia coli O157:H7 translocation and decontamination for beef vacuum-packaged subprimals destined for nonintact use. J. Food Prot. 74:1048-1053. 
Leng, X., Y. Wang, S. Liu, Q. Pei, X. Cui, Y. Tu, X. Liu, and J. Huang. 2017. Enzymatic repairing amplification-based versatile signal-on fluorescence sensing platform for detecting pathogenic bacteria. Sens. Actuators B Chem. 252:689-696.

Luo, K., L. Hu, Q. Guo, C. Wu, S. Wu, D. Liu, Y. Xiong, and W. Lai. 2017. Comparison of 4 label-based immunochromatographic assays for the detection of Escherichia coli O157: H7 in milk. J. Dairy Sci. 100:5176-5187.

Ma, K., Y. Deng, Y. Bai, D. Xu, E. Chen, H. Wu, B. Li, and L. Gao. 2014. Rapid and simultaneous detection of Salmonella, Shigella, and Staphylococcus aureus in fresh pork using a multiplex real-time PCR assay based on immunomagnetic separation. Food Control 42:87-93.

Oh, S. W., Y. M. Kim, H. J. Kim, S. J. Kim, J. S. Cho, and E. Y. Choi. 2009. Point-of-care fluorescence immunoassay for prostate specific antigen. Clin. Chim. Acta 406:18-22.

Paton, J. C., and A. W. Paton. 1998. Pathogenesis and diagnosis of Shiga toxin-producing Escherichia coli infections. Clin. Microbiol. Rev. 11:450-479.

Ratnam, S., S. March, B. R. Ahmed, G. S. Bezanson, and S. Kasatiya 1988. Characterization of Escherichia coli serotype O157: H7. J. Clin. Microbiol. 26:2006-2012.

Sajid, M., A.-N. Kawde, and M. J. Daud. 2015. Designs, formats and applications of lateral flow assay: A literature review. J. Saudi Chem. Soc. 19:689-705.

Shan, S., D. Liu, Q. Guo, S. Wu, R. Chen, K. Luo, L. Hu, Y. Xiong, and W. Lai. 2016. Sensitive detection of Escherichia coli O157:H7 based on cascade signal amplification in ELISA. J. Dairy Sci. 99:7025-7032.

Song, L., L. Zhang, Y. Huang, L. Chen, G. Zhang, Z. Shen, J. Zhang, Z. Xiao, and T. Chen. 2017. Monitoring of Escherichia coli O157: $\mathrm{H} 7$ in food samples using lectin based surface plasmon resonance biosensor. Sci. Rep. 7:3288.

Tsiraki, M. I., H. M. Yehia, T. Elobeid, T. Osaili, H. Sakkas, and I. N. Savvaidis. 2018. Viability of and Escherichia coli O157:H7 and Listeria monocytogenes in a delicatessen appetizer (yogurt-based) salad as affected by citrus extract (Citrox) and storage temperature. Food Microbiol. 69:11-17.
Wang, J., L. Zhang, Y. Huang, A. Dandapat, L. W. Dai, G. Zhang, X. Lu, J. W. Zhang, W. H. Lai, and T. Chen. 2017a. Hollow AuAg nanoparticles labeled immunochromatography strip for highly sensitive detection of clenbuterol. Sci. Rep. 7:41419.

Wang, W., M. Feng, D. Kong, L. Liu, S. Song, and C. Xu. 2015. Development of an immunochromatographic strip for the rapid detection of Pseudomonas syringae pv. maculicola in broccoli and radish seeds. Food Agric. Immunol. 26:738-745.

Wang, W., L. Liu, S. Song, L. Xu, H. Kuang, J. Zhu, and C. Xu. 2017b. Identification and quantification of eight Listeria monocytogene serotypes from Listeria spp. Using a gold nanoparticle-based lateral flow assay. Mikrochim. Acta 184:715-724.

Wang, W., L. Liu, S. Song, L. Xu, J. Zhu, and H. Kuang. 2017c. Gold nanoparticle-based paper sensor for multiple detection of 12 Listeria spp. by P60-mediated monoclonal antibody. Food Agric. Immunol. 28:274-287.

Wang, W., L. Liu, L. Xu, H. Kuang, J. Zhu, and C. Xu. 2016a. Goldnanoparticle-based multiplexed immunochromatographic strip for simultaneous detection of staphylococcal enterotoxin A, B, C, D, and E. Part. Part. Syst. Charact. 33:388-395.

Wang, X., N. Choi, Z. Cheng, J. Ko, L. Chen, and J. Choo. 2017d. Simultaneous detection of dual nucleic acids using a SERS-based lateral flow assay biosensor. Anal. Chem. 89:1163-1169.

Wang, X., Y. Hu, and H. Wei. 2016b. Nanozymes in bionanotechnology: From sensing to therapeutics and beyond. Inorg. Chem. Front. 3:41-60.

Wang, Y., Z. Z. Ye, C. Y. Si, and Y. B. Ying. 2013. Monitoring of Escherichia coli $\mathrm{O} 157: \mathrm{H} 7$ in food samples using lectin based surface plasmon resonance biosensors. Food Chem. 136:1303-1308.

Zeinhom, M. M. A., Y. Wang, Y. Song, M.-J. Zhu, Y. Lin, and D. Du. 2018. A portable smart-phone device for rapid and sensitive detection of E. coli O157:H7 in yoghurt and egg. Biosens. Bioelectron. 99:479-485.

Zhang, L., Y. Huang, J. Wang, Y. Rong, W. Lai, J. Zhang, and T. Chen. 2015. Flowerlike gold nanoparticles labeled immunochromatography test strip for highly sensitive detection of Escherichia coli O157:H7. Langmuir 31:5537-5544. 